Myasthenia gravis: subgroup classification and therapeutic strategies. Lancet Neurol, 14(10), 1023-1036. doi:10.1016/S1474-4422(15)00145-3

4. Vincent A, \& Newsom Davis J. (1980). Antiacetylcholine receptor antibodies. J Neurol Neurosurg Psychiatry, 43(7), 590-600. doi:10.1136/jnnp.43.7.590

5. Thanvi B R, \& Lo T C. (2004). Update on myasthenia gravis. Postgrad Med J, 80(950), 690700. doi:10.1136/pgmj.2004.018903

6. Nguyến Hữu Công. (2013). Chẩn đoán điện và ứng dụng lâm sàng: Nhà xuất bản Đại học quốc gia thành phố Hồ Chí Minh.

7. Kim K H, Kim S W, \& Shin H Y. (2021). Initial Repetitive Nerve Stimulation Test Predicts
Conversion of Ocular Myasthenia Gravis to Generalized Myasthenia Gravis. J Clin Neurol, 17(2), 265-272. doi:10.3988/jcn.2021.17.2.265

8. Oh S J, Jeong D, Lee I, et al. (2019). Repetitive nerve stimulation test in myasthenic crisis. Muscle Nerve, 59(5), 544-548. doi:10.1002/mus.26390

9. Witoonpanich R, Barakul S, \& Dejthevaporn C (2006). Relative fatigability of muscles in response to repetitive nerve stimulation in myasthenia gravis. J Med Assoc Thai, 89(12), 2047-2049.

10. Jing F, Cui F, Chen Z, et al. (2015). Clinical and Electrophysiological Markers in Myasthenia Gravis Patients. Eur Neurol, 74(1-2), 22-27. doi: $10.1159 / 000431284$

\title{
TÌNH TRẠG THIẾU MÁU VÀ DỰ TRŨ̃ SẮT Ở PHỤ NỮ 15 - 35 TUỔI TẠI HUYÊ̂N MƯỜNG LA, TỈNH SƠN LA NĂM 2018
}

\section{TÓM TẮT}

Thiếu máu là vấn đề có ý nghĩa sức khỏe cộng đồng, phụ nữ tuổi sinh đẻ tại khu vực nông thôn, miền núi là đối tượng có nguy cơ thiếu máu cao. Nghiên cứu mô tả cắt ngang trên 395 phụ nữ 15-35 tuổi tại 5 xã thuộc huyện Mường La, tỉnh Sơn La để mô tả tình trang thiếu máu, dự trữ sắt. Kết quả nghiên cứu cho thấy tỷ lệ thiếu máu là $26,3 \%$ trong đó tỷ lệ thiếu máu ở nhóm 15-24 tuổi cao hơn nhóm 25-35 tuổi. Giá trị trung bình hàm lượng Hemoglobin của nhóm $15-25$ tuổi và $25-35$ tuổi là $125,9 \mathrm{~g} / \mathrm{l}$ và $129,5 \mathrm{~g} / \mathrm{l}$ $(p<0,05)$. Tỷ lệ thiếu máu theo mức độ giữa các xã có sự khác biệt, cao nhất ở xã Mường Trai $(18,9 \%)$, thấp nhất ở xã Chiêng Lao $(2,2 \%)(p<0,001)$. Tỷ lệ dự trữ sắt can kiệt và dự trữ sắt thấp lần lượt là $11,4 \%$ và $10,1 \%$; trong đó tỷ lệ dự trữ sắt thấp và cạn kiệt giảm dần theo độ tuổi tăng đân, ở lớp tuổi $15-24$ tuổi là $27,5 \%$ và $25-35$ tuổi là $17,4 \%(p<0,05)$. Tỷ lệ thiếu máu thiếu sắt là 3,8\%, nhưng thiếu máu không thiếu sắt là $22,5 \%$. Ngoài nguyên nhân thiếu máu do thiếu sắt, cần xác định thêm các nguyên nhân khác gây ra tình trang thiếu máu ở PNTSĐ khu vức dân tốc miền núi.

Tư khóa: thiếu máu, dự trữ sắt cạn kiệt, dự trữ sắt, phụ nữ tuổi sinh đẻ, Hemoglobin, Ferritin

\section{SUMMARY \\ ANEMIA AND IRON STORE STATUS IN WOMEN \\ AGED 15-35 YEARS OLD IN MUONG LA \\ DISTRICT, SON LA PROVINCE IN 2018}

Anemia is a significant public health problem, women of reproductive age living in the rural or mountainous areas are at high risk for anemia. A

${ }^{1}$ Viện Dinh dưỡng Quốc gia

Chiu trách nhiệm chính: Nguyễn Thúy Anh

Email: nguyenthuyanh@dinhduong.org.vn

Ngày nhận bài: 17.5.2021

Ngày phản biện khoa học: 8.7.2021

Ngày duyệt bài: 16.7.2021 descriptive cross-sectional study was conducted on 395 women aged 15-35 years old in 5 communes of Muong La district, Son La province to assess anemia and iron store status. The study results showed that the prevalance of anemia was $26.3 \%$, in which the rate of anemia in the 15-24 year old group was higher than the 25-35 year old group. The mean of Hemoglobin concentration of the 15-25 years old and $25-35$ year old groups were $125.9 \mathrm{~g} / \mathrm{l}$ and $129.5 \mathrm{~g} / \mathrm{l}$, respectively $(p<0.05)$. There was a significant difference in the prevalance of anemia by level between the communes, the highest in Muong Trai commune $(18.9 \%)$, the lowest in Chieng Lao $(2.2 \%)$ $(p<0.001)$. The prevalance of depleted iron stores and low iron stores is $11.4 \%$ and $10.1 \%$ respectively, in which the rate of low and depleted iron stores decreases with increasing age, in the age group of 1524 years old, it is $27.5 \%$ and $25-35$ years old is $17.4 \%$ $(p<0.05)$. The prevalance of iron deficiency anemia was $3.8 \%$, but anemia without iron deficiency was $22.5 \%$. In addition to iron deficiency anemia, it is necessary to identify other causes of anemia in women of reproductive age in ethnic minority and moutainous area.

Keywords: anemia, depleted iron stores, iron stores, women of reproductive age, haemoglobin, ferritin

\section{I. ĐĂT VẤN ĐỀ}

Trong các vấn đề dinh dưỡng ở phụ nữ lứa tuổi sinh đẻ, thiếu máu thiếu sắt là vấn đề sức khỏe cần quan tâm. Thiếu máu gây hậu quả nặng nề, ảnh hưởng xấu đến sức khỏe con người và sư phát triển kinh tế xã hội, là nguyên nhân làm tăng tỷ lệ mắc bệnh và tử vong. Theo báo cáo của Tổ chức Y tế thế giới (WHO) năm 2011, thiếu máu ảnh hưởng đến gần 800 triệu trẻ em và phụ nữ, trong đó có khoảng 528,7 triệu phụ nữ trong độ tuổi sinh đẻ bị thiếu máu chiếm $29,4 \%$. Tỷ lệ thiếu máu hiện mắc cao nhất ở 
Trung Phi, Đông Phi và Nam Á. Tại Việt Nam, theo điều tra vi chất 2014-2015 của Viện Dinh dưỡng Quốc gia cho thấy tỷ lệ thiếu máu ở phụ nữ tuổi sinh đẻ (PNTSĐ) là 25,5\% trong đó tâp trung cao hơn ở miền núi $(27,9 \%)$ (thiếu máu do thiếu sắt chiếm $37,7 \%)$ và nông thôn $(26,3 \%)$ thấp hơn ở khu vực đồng bằng $(20,8 \%)[1]$. Kết quả nghiên cứu tại một huyện miền núi tỉnh Cao Bằng cho thấy tỷ lệ thiếu máu PNTSĐ dân tộc Dao là $31,3 \%$ và có xu hướng giảm dần theo nhóm tuổi; tỷ lệ thiếu sắt là 7,6\% [2]. Có nhiều nguyên nhân dẫn đến tình trạng thiếu máu, trong đó thiếu máu do thiếu sắt chiếm tới $50 \%$ tổng số người thiếu máu ở các nước đang phát triển. Ngoài ra có một số nguyên nhân khác dẫn đến tình trạng thiếu máu như nhiễm giun, mắc các bệnh lý khác như bệnh thalassemia, bệnh tan huyết.

Huyên Mường La là huyên miền núi thuộc tỉnh Sơn La có tổng dân số 97,7 nghìn người trong đó trên $90 \%$ là dân tộc thiểu số bao gồm dân tộc Thái, Mông, Khơ Mú, Kháng, La Ha. Đây là huyện nghèo, nơi tỷ lệ suy dinh dưỡng trẻ em khá cao; có nhiều bằng chứng lâm sàng cho thấy tình trạng vi chất dinh dưỡng của mẹ và trẻ có mối liển quan chặt chẽ với nhau. Thiếu vi chất dinh dưỡng, thiếu máu ở phụ nữ tuổi sinh đẻ làm tăng nguy cơ biến chứng cho me và con khi sinh như mẹ dễ bị các tai biến sản khoa, trẻ sinh ra có cân nặng sơ sinh thấp [3]. Chính vì vậy, xác định thực trang thiếu máu ở PNTSĐ là một trong những nhiệm vụ cần thiết. Do đó, chúng tôi tiến hành nghiển cứu này với mục tiêu đánh giá tình trạng thiếu máu và dự trữ sắt ở của phụ nữ 15 35 tuổi của huyên Mường La, tỉnh Sơn La để từ đó đề xuất ra các giải pháp can thiệp phù hợp.

\section{II. ĐỐI TƯƠNGG VÀ PHƯƠNG PHÁP NGHIÊN CỨU 2.1 Đối tượng, địa điểm và thời gian nghiên cứu: \\ Đôi tượng đáp ứng các tiêu chí:}

- Phụ nữ trong độ tuổi 15-35, không nuôi con bú dưới 12 tháng, không có thai; không có dị tât, không mắc các bệnh về máu, các bệnh nhiếm trùng cấp.

- Có phiếu cam kết chấp thuận tham gia nghiên cứu.

Địa điểm và thời gian: tại 5 xã của huyện Mường La, tỉnh Sơn La trong thời gian từ tháng 07/2018 đến tháng 12/2018.

\subsection{Thiết kế nghiên cứu: Mô tả cắt ngang}

\subsection{Cỡ mẫu:}

*Xác định tình trạng thiêu máu:

Áp dụng công thức tính cõ mẫu:

$$
\mathrm{n}=\frac{\mathrm{Z}^{2}(1-\mathrm{a} / 2) \cdot \mathrm{p}(1-\mathrm{p}) \times \mathrm{DE}}{\mathrm{d}^{2}}
$$

Trong đó: $\mathrm{n}$ là số đối tượng cần điều tra, với p là tỷ lệ thiếu máu phụ nữ không có thai ở miền núi, năm 2015 là $27,9 \%$ [1]; chọn $d=0,05 ; z$ có giá trị là 1,96. $\mathrm{DE}=1,2 ;$; Cõ mâuu cần là 372 đối tượng.

*Tinh trạng dứ trữ sắt cạn kiệt. Với $\mathrm{p}$ tỷ lệ phụ nữ khồng có thai dự trữ sắt cạn kiệt năm 2017 là $9,1 \%[4]$; chọn $d=0,05 ; z$ có giá trị là 1,96; DE x 1,2; Tính toán được cõ mẫu cần là 154.

Cõ̃ mẫu cần chung là 372 ; thêm $10 \%$ đề phòng các trường hợp đối tượng bỏ cuộc. Do đó cõ mẩu lựa chọn là 409 đối tượng. Thực tế điều tra 395 đối tượng.

\subsection{Phương pháp chọn mẫu:}

Chọn tỉnh: Chọn chủ đích huyện Mường La, tỉnh Sớn La một trong những tỉnh miền núi phía Bắc, nơi có hoàn cảnh kinh tế khó khăn.

Chọn xã: Chọn ngẫu nhiên đơn 5 xã trong 9 xã thuộc xã nghèo thuộc huyện Mường La được chọn (là xã Chiềng Lao, Nậm Giôn, Mường Trai, Hua Trai, Ngọc Chiến)

Chọn đối tượng nghiên cứu: theo phương pháp ngẫu nhiên hệ thống.

\subsection{Phương pháp và công cụ thu thập} số liệu

+ Tính tuổi của phu nữ từ 15 - 35 tuổi: Toàn bộ những phụ nữ trong độ tuổi từ tròn 15 tuổi cho đến tròn 35,9 tuổi.

+ Phỏng vấn: Sử dụng bộ câu hỏi được xây dựng có tham khảo các cuộc điêuu tra về thiếu máu. Bộ câu hỏi được thử nghiệm trước khi điều tra.

+ Xét nghiệm máu: Định lượng Hemoglobin $(\mathrm{Hb})$ trong máu bằng phương pháp Cyamethemoglobin, dùng máy Hemocue; Chẩn đoán thiếu thiếu sắt trong giai đoạn sớm dựa vào nồng độ Ferritin huyêt thanh (SF) bằng phương pháp ELISA. Chẩn đoán thiếu máu thiếu sắt trong giai đoan sớm dựa vào nồng độ Ferritin huyết thanh (SF) bằng phương pháp ELISA với chuẩn Ferritin huyết thanh.

\subsection{Một số tiêu chuẩn xác định, đánh giá}

+ Tình trạng thiếu máu: khi hàm lượng Hemoglobin trong máu $<120 \mathrm{~g} / \mathrm{l}$, trong đó thiếu máu nặng khi $\mathrm{Hb}<70 \mathrm{~g} / \mathrm{l}$; thiếu máu trung bình khi $70 \mathrm{~g} / \mathrm{l} \leq \mathrm{Hb}<100 \mathrm{~g} / \mathrm{l}$ và thiếu máu nhẹ khi $100 \mathrm{~g} / \mathrm{l} \leq \mathrm{Hb}<120 \mathrm{~g} / \mathrm{l} ;$ xác định tình trang dự trữ sắt dựa vào nồng Ferritin huyết thanh (SF) bằng phương pháp ELISA. Khi hàm lượng Ferritin huyết thanh nhỏ hơn $30 \mu \mathrm{g} / \mathrm{l}$ là tình trạng dự trũ sắt thấp; nhỏ hơn $15 \mu \mathrm{g} / \mathrm{l}$ là tình trạng dự trữ sắt huyết thanh đã cạn kiệt nặng. Thiếu máu thiếu sắt khi (ferritin huyết thanh $<15 \mu \mathrm{g} / \mathrm{l}$ và 
Hemoglobin $<120 \mathrm{~g} / \mathrm{l}$ )

2.7. Phân tích và xử lý số liệu: Sử dụng phần mềm Epi Data 3.1 để nhập liệu và phần mềm SPSS 18.0 để phân tích. Test kiểm định thống kê là $\chi^{2}$ test, $\mathrm{t}$ - test độc lập so sánh giá trị trung bình 2 nhóm, ANOVA test so sánh giá trị trung bình của 3 nhóm và phân tích hồi qui logistic và tương quan tuyến tính đa biến dự đoán các yếu tố liên quan. Nồng độ hemoglobin phân bố chuẩn; Ferritin phân bố không chuẩn. Giá trị $\mathrm{p}<0,05$ được xem có ý nghĩa thống kê (YNTK).

2.8. Đạo đức nghiên cứu: Nghiên cứu đã được chấp thuận bởi Hội đồng đạo đức của Viện Dinh dưỡng trước khi triển khai, theo quyết định số theo quyết định số 1474 /QĐ-VDD ngày $14 / 09 / 2018$.

\section{KẾT QUẢ NGHIÊN CỨU}

3.1. Thông tin chung về đối tượng điêu tra. Nghiên cứu đã tiến hành trên 395 phụ nữ 15-35 tuổi tại 5 xã thuộc huyện Mường La, tỉnh Sơn La; thuộc huyện nghèo của tỉnh miền núi phía Bắc có $79,5 \%$ đối tượng nghiên cứu là người Thái, $12,4 \%$ dân tộc H'mông; còn lại 8,1\% là các dân tộc khác bao gồm cả dân tộc Kinh. Tuổi trung bình của đối tượng là $25,6 \pm 6,7$; Kinh tế hộ gia đình 47,8\% là hộ nghèo và 19,2\% là cận nghèo; còn lại 32,9\% bình thường; Nông nghiệp vần nghề nghiệp đem lại thu nhập chính cho các gia đình $81,0 \%$, bên cạnh đó có $16,5 \%$ đối tượng là học sinh; Số người trong hộ gia đình trung bình là $5,2 \pm 1,6$.

\subsection{Tình trạng thiếu máu của đối tượng nghiên cứu}

Bảng 1. Tình trạng thiếu máu ở đôî tượng nghiên cứu theo nhóm tuổi

\begin{tabular}{|c|c|c|c|c|}
\hline Nhóm tuối & $\mathbf{n}$ & Số thiếu máu & Tỷ lê (\%) & Giá trị TB Hb (g/I) \\
\hline 15-24 tuối & 160 & 48 & $30,0^{\mathrm{b}}$ & $125,9 \pm 17,4^{\mathrm{c} 1}$ \\
\hline 25-35 tuối & 235 & 56 & 23,8 & $129,5 \pm 17,7$ \\
\hline 15-19 tuối & 91 & 28 & $30,8^{\mathrm{b}}$ & $126,4 \pm 16,8^{\mathrm{a}}$ \\
\hline 20-24 tuối & 69 & 20 & 29,0 & $125,3 \pm 18,2$ \\
\hline 25-29 tuối & 103 & 24 & 23,3 & $129,7 \pm 16,9$ \\
\hline 30-35 tuối & 132 & 32 & 24,2 & $129,4 \pm 18,3$ \\
\hline Chung & 395 & 104 & 26,3 & $128,1 \pm 17,9$ \\
\hline
\end{tabular}

a) ANOVA-test cho so sánh giá trị trung bình nhưng sự khác biệt không có YNTK ( $\chi^{2}$ test, $\mathrm{p}>$ Hemoglobin giữa 4 nhóm tuổi, với p>0,05

b) $\chi^{2}$ test so sánh tỷ lệ thiếu máu giữa 2 nhóm tuổi và 4 nhóm tuổi, với $p>0,05$.

c) t-test cho so sánh giá trị trung bình Hemoglobin giữa 2 nhóm tuổi ${ }^{1} p<0,05$

Tỷ lệ thiếu máu ở nhóm 15 - 24 tuổi là 30,0\% cao hơn so với nhóm 25 - 35 tuổi $(23,8 \%)$, $0,05)$. Giá trị trung bình hàm lượng Hemoglobin có sự khác biệt có YNTK giữa 2 nhóm ( $\mathrm{t}$ - test, $\mathrm{p}$ $<0,05)$.

Tình trạng thiếu máu ở 4 nhóm tuổi cho thấy tỷ lệ thiếu máu cao nhất ở nhóm 15-19 tuổi $(30,8 \%)$; nhưng sự khác biệt về tỷ lệ giữa 4 nhóm tuổi chưa có YNTK $\left(\chi^{2}\right.$ test, $\left.p>0,05\right)$.

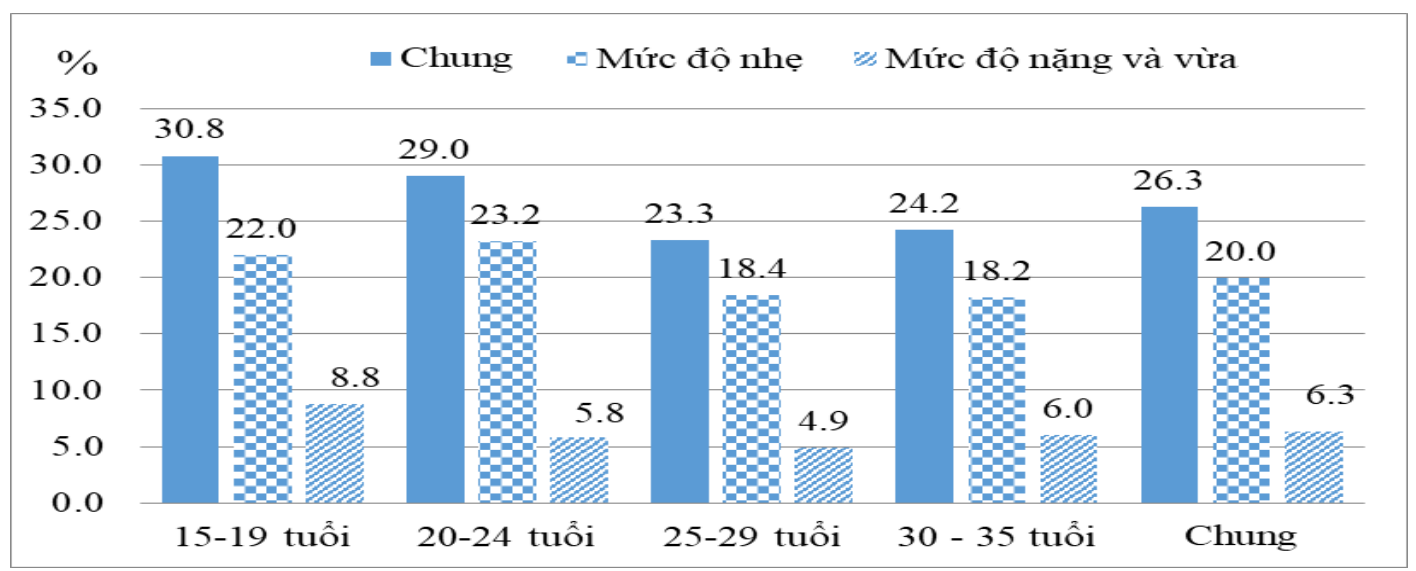

$\chi^{2}$ test so sánh tỷ lệ thiếu máu theo mức độ với $\mathrm{p}>0,05$.

Hình 1. Tỷ lệ thiếu máu theo mức độ thiếu máu và theo nhóm tuổi

Tỷ lệ thiếu máu mức độ nặng và vừa cao nhất ở nhóm 15 - 19 tuổi $(8,8 \%)$, tiếp theo là 30-35 tuổi $(6,0 \%)$; nhóm 25-29 tuổi là thấp nhất $(4,9 \%)$; Không có sự khác biệt có ý nghĩa về tỷ lệ thiếu máu theo mức độ giữa 4 nhóm tuổi ( $\chi^{2}$ test, $\left.p>0,05\right)$. 


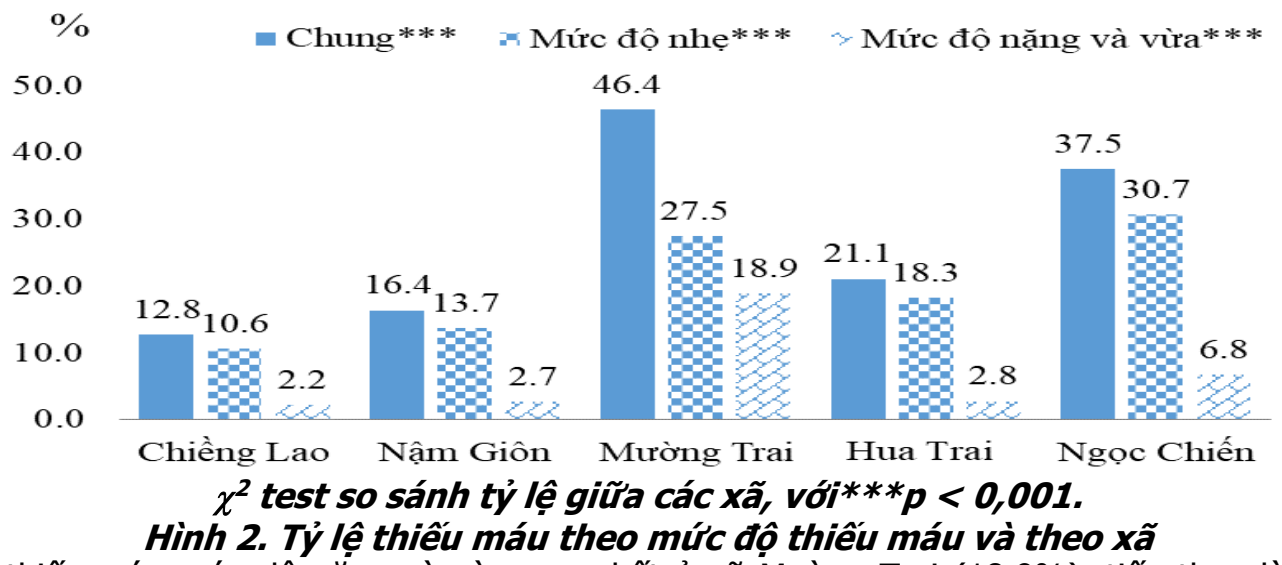

Tỷ lệ thiếu máu mức độ nặng và vừa cao nhất ở xã Mường Trai $(18,9 \%)$, tiếp theo là xã Ngọc Chiến $(6,8 \%)$; xã Chiềng Lao là thấp nhất $(2,2 \%)$; Có sự khác biệt có ý nghĩa về tỷ lệ thiếu máu theo mức độ và chung giữa các xã ( $\chi^{2}$ test, $\left.p<0,001\right)$.

3.3. Tình trạng dự trữ sắt thấp và cạn kiệt ở đối tượng nghiên cứu

Bảng 2. Tình trạng dự trữ sắt thấp và cạn kiệt theo các nhóm tuổi

\begin{tabular}{|c|c|c|c|c|c|c|c|c|c|}
\hline \multirow{2}{*}{$\begin{array}{c}\text { Nhóm } \\
\text { tuối }\end{array}$} & \multirow[b]{2}{*}{$\mathbf{n}$} & \multicolumn{2}{|c|}{$\begin{array}{l}\text { Dự trữ sắt thấp } \\
\text { và can kiệt }\end{array}$} & \multicolumn{2}{|c|}{$\begin{array}{c}\text { Thiếu sắt không } \\
\text { thiếu máu }\end{array}$} & \multicolumn{2}{|c|}{$\begin{array}{l}\text { Thiếu máu } \\
\text { thiếu sắt }\end{array}$} & \multicolumn{2}{|c|}{$\begin{array}{l}\text { Thiếu máu } \\
\text { không thiếu sắt }\end{array}$} \\
\hline & & $\mathbf{n}$ & $\%$ & $n$ & $\%$ & $\mathbf{n}$ & $\%$ & $\mathbf{n}$ & $\%$ \\
\hline 15-24 tuối & 160 & 44 & $27,5^{\mathrm{b} 1}$ & 18 & $11,3^{\mathrm{b} 1}$ & 8 & 5,0 & 40 & 25,0 \\
\hline $25-35$ tuối & 235 & 41 & 17,4 & 12 & 5,1 & 7 & 3,0 & 49 & 20,9 \\
\hline 15-19 tuổi & 91 & 24 & 26,4 & 8 & 8,8 & 6 & 6,6 & 22 & 24,2 \\
\hline $20-24$ tuổi & 69 & 20 & 29,0 & 10 & 14,5 & 2 & 2,9 & 18 & 26,1 \\
\hline $25-29$ tuổi & 103 & 19 & 18,4 & 8 & 7,8 & 1 & 1,0 & 23 & 22,3 \\
\hline 30-35 tuổi & 132 & 22 & 16,7 & 4 & 3,0 & 6 & 4,5 & 26 & 19,7 \\
\hline Chung & 395 & 85 & 21,5 & 30 & 7,6 & 15 & 3,8 & 89 & 22,5 \\
\hline
\end{tabular}

b) $\chi^{2}$ test so sánh tỷ lệ giữa 2 nhóm tuổi, 4 nhóm tuối; với ${ }^{1} p<0,05$.

Tyy lệ dự trữ sắt thấp và cạn kiệt là $21,5 \%$; thiếu máu thiếu sắt là $3,8 \%$; có $7,6 \%$ trường hợp thiếu sắt nhửng không thiếu máu và $22,5 \%$ trường hợp thiếu máu không thiếu sắt.

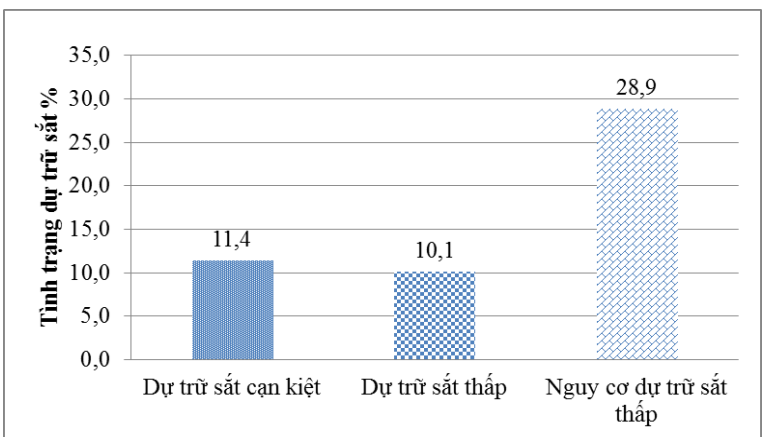

Hình 3. Tỷ lệ dự trữ sắt thấp và cạn kiệt ở đôi tượng nghiên cứu

Tỷ lệ dự trữ sắt cạn kiệt là $11,4 \%$; tỷ lệ dự trữ sắt thấp là $28,9 \%$. Ngoài ra nguy cơ dự trữ sắt thấp là $28,9 \%$.

\section{BÀN LUÂN}

4.1. Tình trạng thiếu máu ở đối tượng nghiên cứu. Tỷ lệ thiếu máu của phụ nữ huyện Mường La là $26,3 \%$ và ở mức trung bình về ý nghĩa sức khỏe cộng đồng. Tỷ lệ này cao hơn tỷ lê thiếu máu của PNTSĐ ở tỉnh Nam Định $(23,2 \%)$ [5] và nghiên cứu ở Bắc Giang $(16,2 \%)$ [6], nhưng lại thấp hơn tỷ lệ thiếu máu của PNTSĐ người Dao ở tỉnh Cao Bằng $(31,3 \%)$ [2]. Điều này cho thây tỷ lệ thiếu máu phụ thuộc vào điều kiện kinh tế, xã hội của địa phương.

So sánh tỷ lê thiếu máu giữa 2 nhóm tuổi cho thấy tỷ lệ thiếu máu ở nhóm 15 - 24 tuổi là $30,0 \%$ cao hơn so với nhóm 25-35 tuổi $(23,8 \%)$, sự khác biêt này không có YNTK $\left(\chi^{2}\right.$ test, $p>$ $0,05)$. Tỷ lệ thiếu máu này thấp hơn so với tỷ lệ thiếu máu ở 2 nhóm tuổi tương đương trong nghiên cứu ở Cao Bằng (39,1\% và 27,9\%) [2], kết quả ở cả 2 nghiên cứu cho thấy tỳ lệ thiếu máu đều giảm dần theo độ tuổi tăng dần.

Giá trị trung bình hàm lượng Hemoglobin có sự khác biệt có YNTK giữa 2 nhóm tuổi; nhóm 15-24 tuổi thấp hơn $(125,9 \mathrm{~g} / \mathrm{l})$ so với nhóm $25-$ 35 tuổi $(129,5 \mathrm{~g} / \mathrm{l})$ (t- test, $\mathrm{p}<0,05)$. Hàm lượng $\mathrm{Hb}$ trung bình của đối tượng nghiên cứu là 128,1 g/l. Kết quả này thấp hơn kết quả nghiên cứu ở 
Bắc Giang $(129,8 \mathrm{~g} / \mathrm{l})[6]$ nhưng lại cao hơn kết quả nghiên cứu ở Cao Bằng $(122,3 \mathrm{~g} / \mathrm{l})$ [2].

So sánh tỷ lệ thiếu máu mức độ nặng và vừa ở 4 nhóm tuổi cho thây sự khác biệt không có YNTK. Tuy nhiên, có sư chênh lêch nhiều về tỷ lê thiếu máu chung và thiếu máu theo mức độ nặng và vừa giữa các xã, tỷ lệ thiếu máu chung và theo mức độ nặng và vừa cao nhất là ở xã Mường Trai $(46,4 \%$ và $18,9 \%)$ và thấp nhất là ở xã Chiêng Lao $(12,8 \%$ và $2,2 \%)$; sự khác biệt này có ý nghĩa thống kê $\left(\chi^{2}\right.$ test, $\left.p<0,001\right)$. Lý giải cho tỷ lệ thiếu máu chênh lệch giữa các xã có thể do sự khác nhau về điều kiên kinh tế cũng như nhận thức của người dân ở từng xã.

4.2. Tình trạng dự trữ sắt ở đối tượng nghiên cứu. Kết quả nghiên cứu cho thây tỷ lệ dự trữ sắt cạn kiệt (ferritin huyết thanh $<15$ $\mu \mathrm{g} / \mathrm{L})$ của phụ nữ ở 5 xã ở huyện Mường La, Sơn La là 11,4\%; cao hơn kết quả ở phụ nữ sau sinh 6 tháng tại Phú Bình, Thái Nguyên $(9,1 \%)$ [4] nhưng lại thấp hơn nhiều so với nghiên cứu ở PNTSĐ tại Yên Bái $(23,10 \%)$ [7]. Dự trữ sắt cạn kiệt hay thiếu sắt được coi là một trong những nguyên nhân gây thiếu máu. Tuy nhiên, trong nghiên cứu này tỷ lệ phụ nữ thiếu máu ở 5 xã là $26,3 \%$, nhưng chỉ có $11,4 \%$ đối tượng có dự trũ sắt cạn kiệt. Đồng thời, tỷ lệ thiếu máu thiếu sắt là $3,8 \%$ và có $22,5 \%$ đối tượng nghiên cứu thiếu máu không thiếu sắt. Kết quả này gần tương tự kết quả ở Cao Bằng với tỷ lệ thiếu máu thiếu sắt và thiếu máu không thiếu sắt ở PNTSĐ người Dao là $4,2 \%$ và $27,1 \%$ [2]. Tuy nhiên, khi so sánh với kết quả nghiên cứu của tác giả Trân Thi Hồng Vân cho thấy tỷ lệ thiếu máu do thiếu sắt ở PNTSĐ người dân tộc Tày ở Phú Lương, Thái Nguyên chiếm tỷ lê cao 45,0\% [8]. Do đó, có thể cho rằng thiếu sắt hay dự trữ sắt cạn kiệt chưa phải là nguyên nhân quan trọng gây ra tình trạng thiếu máu của PNTSĐ ở huyện Mường La, Sởn La và cần phải có các nghiên cứu khác tìm hiểu về nguyên nhân thiếu máu tại nơi đây.

Trong bảng 2 , tỷ lệ dự trữ sắt thấp và cạn kiệt giảm dần theo độ tuổi, ở lớp tuổi 15 - 24 tuổi là $27,5 \%$ cao hơn có YNTK so với lớp tuổi $25-35(17,4 \%),\left(\chi^{2}\right.$ test, $\left.p<0,05\right)$. Kết quả này cũng cao hơn nghiên cứu ở PNTSĐ tại Nam Định [5], tuy nhiên kết quả của nghiên cứu tại Nam Định cũng có xu hướng giảm dân theo độ tuổi.

Qua kết quả nghiên cứu của chúng tôi và một số kết quả nghiên cứu khác được đề cập ở trên, có thể thấy tỷ lệ thiếu máu và dự trữ sắt thấp và cạn kiệt ở PNTSĐ tại vùng miền núi phía Bắc vẫn còn khá cao so với các khu vực khác. Thiếu máu do nhiêu nguyên nhân khác nhau, trong nghiên cứu này cũng có hạn chế nhất định do chưa tìm hiểu về nguyên nhẩn gây ra tình trạng thiếu máu của phụ nữ ở huyện Mường La, Sơn La. Nghiên cứu khuyến nghị cần tiếp tục tăng cường công tác truyên thông giáo dục dinh dưỡng, tăng cường bổ sung sắt cho phụ nữ trong độ tuổi sinh đẻ để cải thiện tình trạng thiếu máu và dự trữ sắt.

\section{KẾT LUÂN}

Tỷ lệ thiếu máu ở PNTSĐ tại huyện Mường La, Sơn La là 26,3\%; trong đó tỳ lệ thiếu máu ở nhóm 15-24 tuổi cao hơn nhóm 25-35 tuổi, nhưng không có YNTK. Hàm lượng Hemoglobin trung bình của nhóm 25-35 tuổi $(129,5 \mathrm{~g} / \mathrm{l})$ cao hơn có YNTK so với nhóm 15-24 tuổi $(125,9 \mathrm{~g} / \mathrm{l})$ $(p<0,05)$. Có sự khác biệt có ý nghĩa thống kê về tỷ lệ thiếu máu theo mức độ giữa các xã, cao nhất ở xã Mường Trai $(18,9 \%)$, thấp nhất ở xã Chiềng Lao $(2,2 \%)(p<0,001)$. Tỷ lệ dự trữ sắt cạn kiệt và dự trữ sắt thấp, lần lượt là $11,4 \%$ và 10,1\%; Tỷ lệ dự trữ sắt thấp và cạn kiệt ở nhóm tuổi 15 - $24(27,5 \%)$ cao hơn có ý nghĩa thống kê so với nhóm $25-35$ tuổi $(17,4 \%)(p<0,05)$. Tỷ lệ thiếu máu thiếu sắt chung là $3,8 \%$, tỷ lệ thiếu máu nhưng không thiếu sắt là $22,5 \%$. Ngoài nguyên nhân thiếu máu do thiếu sắt, cần xác định thêm các nguyên nhân khác gây ra tình trạng thiếu máu ở PNTSĐ.

Lời cảm ơn: Tác giả chân thành cảm ơn các cán bộ Trung tâm $Y$ tế Dự phòng tỉnh Sơn La, Trung tâm $Y$ tế huyên Mường La, trạm $Y$ tế 5 xã đã tham gia nghiên cứu này. Nghiên cứu đã sử dụng kinh phí của đề tài nghiên cứu khoa học của Viện Dinh dưỡng năm 2018.

\section{TÀI LIÊU THAM KHẢO}

1. Viện Dinh dưỡng. Tình hình dinh dưỡng chiến lược can thiệp 2011-2015 và định hướng 20162020. Nhà xuất bản Y học, 2017.

2. Nguyễn Văn Điệp, Nguyễn Quang Dũng, Lê Danh Tuyên. Tình trạng thiếu máu ở phụ nữ tuổi sinh đẻ người Dao tại 4 xã thuộc huyện Bảo Lac, tỉnh Cao Bằng. Tạp chí Y học dự phòng, 2017; 27(2): 100-103.

3. Theresa O Scholl (2005). Iron status during pregnancy: setting the stage for mother and infant. The American journal of clinical nutrition, 2005; 81(5): 1218S-1222S.

4. Nguyễn Song Tú, Trân Thúy Nga, Lê Danh Tuyển, Hoàng Văn Phương. Thực trạng dự trữ sắt ở bà me sau sinh 6 tháng và một vài yểu tố liên quan tại Phú Bình. Tạp chí Y hộc dự phòng, 2017. Tập 27, số 6 phụ bản: p. 175-182.

5. Hoàng Thị Thớm, Trần Thúy Nga, Phạm Ngơc Khái. Tình trạng dinh dưỡng, thiếu máu, thiếu kẽm ở phu nữ tuổi sinh đẻ tại 4 xã, Nam Định. Tap chí Dinh dưỡng \& Thực phẩm, 2017; 13(2): 64-68̀.

6. Đinh Thị Phương Hoa, Lê Thi Hợp, Phạm Thi Thúy Hòa. Thực trạng thiếu máu, tình trạng dinh 
dưỡng và nhiễm giun ở phụ nữ 20-35 tuổi tại 6 xã thuộc huyện Lục Nam, Bắc Giang. Tạp chí Dinh dướng \& Thực phẩm, 2012; 8(1): 39-43.

7. Sant-Rayn Pasricha, Tran Q. Phuc, Gerard J. Casey and et al. "Anemia, Iron deficiency, Meat consumption, and Hookworm infection in Women of reproductive age in Northwest VietNam".
American Journal Tropical Medicine Hygiene, 2008 Mar; 78(3), 375-381.

8. Trân Thị Hồng Vân, Lê Thị Hương. Tình trang thiếu năng lượng trường diễn và thiếu máu dinh dưỡng ở phụ nữ 20-35 tuổi người dân tộc Tày tại huyện Phú Lương, tỉnh Thái Nguyên năm 2017. Tạp chí Dinh dưỡng \& Thực phẩm, 2017; 15(1): 25-29.

\section{CHÂT LƯỢNG CUỘC SỐNG LIÊN QUAN ĐẾN SỨC KHỎE CỦA TRẺ HEN PHẾ QUẢN TỪ 8 ĐẾN 12 TUỔI TẠI BỆNH VIỆN NHI TRUNG ƯƠNG}

\section{TÓM TẮT}

Nghiên cứu mô tả cắt ngang được tiến hành nhằm mô tả chất lượng cuộc sống liên quan đến sức khỏe (Health related quality of life - HrQoL) của trẻ hen phế quản (HPQ) từ 8 đến 12 tuổi tại bệnh viện Nhi Trung ương. Kết quả: 123 bệnh nhân đủ tiêu được mời tham gia nghiên cứu từ tháng 7/2020 đến tháng 4/2021. Nhóm nghiên cứu có $69,1 \%$ nam, $94,3 \%$ hen nhẹ, $9,8 \%$ hen kiểm soát hoàn toàn. HrQoL của trẻ theo PedsQL ${ }^{T M} 3.0$ AM có điểm chung là $75,5 \pm 14,88$, trong đó điểm thấp nhất ở lĩnh vực triệu chứng bệnh hen $(66,1 \pm 16,21)$. Đánh giá bằng PedsQL ${ }^{\mathrm{TM}} 4.0$, HrQoL của nhóm trẻ hen phế quản là $77,57 \pm 12,55$ điểm, không khác biệt với trẻ khỏe mạnh cùng độ tuổi; điểm HrQoL thấp nhất ở lĩnh vực cảm xúc $(73,62$ $\pm 19,06)$; về lî́nh vực trường học điểm HrQoL của trẻ $\mathrm{HPQ}$ thấp hơn có ý nghĩa so với nhóm chứng. Kết luận: Hen phế quản ảnh hưởng đến HrQoL, đặc biệt ở khía canh cảm xúc và vấn đề học tâp ở trường.

Tư khóa: Chất lượng cuộc sống liên quan đến sức khỏe, hen phế quản, trẻ em.

\section{SUMMARY \\ HEALTH RELATED QUALITY OF LIFE IN CHILDREN WITH ASTHMA FROM 8 TO 12 YEARS OLD AT THE NATIONAL CHILDREN'S HOSPITAL}

A cross sectional study was conducted to describe health related quality of life (HrQoL) of children with asthma from 8 to 12 years old at the National Children's Hospital. There were 123 children with asthma were recruited for study between $7 / 2020$ to 4/2021. Boys were $69,1 \%$. 94,3\% children suffered from mild asthma and $9,8 \%$ were well controlled asthma. HrQoL of children with asthma were measured by PedsQL 3.0 AM, with mean score were $75,5 \pm 14,88$ with lowest score in asthma symptoms $(66,1 \pm 16,21)$. The general HrQoL score of children

${ }^{1}$ Bệnh viện đa khoa Hoài Đức -Hà Nội.

${ }^{2}$ Trường Đại học Y Hà Nội

Chịu trách nhiệm chính: Nguyễn Thị Thu

Email: thunhi2468@gmail.com

Ngày nhận bài: 17.5.2021

Ngày phản biên khoa họ: 5.7.2021

Ngày duyệt bài: 19.7.2021

\section{Nguyễn Thị Thu ${ }^{1,2}$, Nguyễn Thị Diệu Thúy ${ }^{2}$}

with asthma meassured by PedsQL ${ }^{\mathrm{TM}} 4.0$ were $77,57 \pm 12,55$. This result was similar of healthy children group. Lowest score was seen in emotional functioning $(73,62 \pm 19,06)$. HrQoL in school functioning was significantly lower in comparison with that of HrQoL in healthy children. Conclusions: Asthma affects to HrQoL, especially in emotional and school functionings.

Keyword: Health related quality of life, asthma, children.

\section{I. ĐĂT VẤN ĐỀ}

Hen phế quản (HPQ) là bệnh viêm đường hô hấp mạn tính rất thường gặp ở trẻ em. Trẻ bi HPQ thường hạn chế khả năng học tập, vui chơi, sinh hoạt so với trẻ khỏe mạnh do các triệu chứng của bệnh, chất lượng cuộc sống giảm sút.

Chất lượng cuộc sống là một tiêu chí cân hướng tới khi quản lý các bệnh mạn tính. Chất lượng cuộc sống liên quan sức khỏe (HrQoL) là khà năng thực hiện các chức năng hàng ngày như các hoạt động thể chất, biểu hiện cảm xúc, khả năng tham gia các hoạt động xã hội. HrQoL của bệnh nhân HPQ cung cấp thông tin khách quan và toàn diện về hiệu quả điều trị và những tác động của bệnh đến cuộc sống của trẻ. 1 Từ đó góp phân đưa ra những can thiệp phù hợp, nâng cao chất lượng điêuu trị giúp cải thiện chất lượng cuộc sống.

Năm 2004, Varni thiết kế bộ công cụ PedsQL ${ }^{\text {TM }} 3.0$ đánh giá HrQoL cho các bệnh mạn tính ở trẻ em trong đó có $\mathrm{HPQ}$ (PedsQL ${ }^{\mathrm{TM}} 3.0$ AM). Tại Việt Nam, PedsQL ${ }^{\mathrm{TM}} 3.0$ được áp dụng đánh giá HrQoL trên một số bệnh mạn tính, tuy nhiên chưa có đề tài nào áp dụng trển trẻ $\mathrm{HPQ}$. Chúng tôi tiến hành nghiên cứu với mục tiêu: Mô tả chất lượng cuộc sống liên quan đến sức khỏe ở trẻ HPQ từ 8 - 12 tuổi tại bệnh viện Nhi Trung ương.

\section{II. ĐỐI TƯỢNG VÀ PHƯƠNG PHÁP NGHIÊN CỨU}

1.Đối tượng: Bệnh nhân chẩn đoán xác định HPQ, ngoài cơn hen cấp từ 8-12 tuổi. 